\title{
POWER PROCESSING UNIT FOR MICRO SATELLITE ELECTRIC PROPULSION SYSTEM
}

\author{
Spiridon Savvas, Dimitrios Malamas, Alexandros Manoudis, Pavlos Ramnalis ${ }^{(1)}$, Luca Benetti, Silvia \\ d'Argliano, Luca Onida, Davide Caniglia, Lorenzo Fontani, Tommaso Misuri ${ }^{(2)}$
}

(1) Sitael Hellas S.LTD, Dionisiou Solomou 4, Veria, 59132 Imathia, Greece,Email: spiridon.savvas@sitael-hellas.com (2) Sitael, Via Livornese, 1019 S. Piero a Grado 56122 Pisa, Italy,Email:luca.benetti@sitael.com

\section{ABSTRACT}

The Micro Satellite Electric Propulsion System (MEPS) program has been originated by the increasing need to provide a low-cost and low-power Electric Propulsion System (EPS) for small satellites $(<300 \mathrm{Kg})$ and finds applications in orbit insertion after launcher separation, orbit maintenance, orbit transfers and deorbiting.

The MEPS design was conceived as a "plug and play" subsystem that can be easily installed in a number of small spacecraft platforms, consisting of two Thruster
\end{abstract}

Units (TU), Power Processing Unit (PPU), Xenon Propellant Tank Assembly (PTA) and Propellant Management Assembly (PMA). Being the "heart" of the system, the PPU supplies and monitors all the EPS voltages and currents.

The objective of this paper is to present the design of the PPU whose concept is focused on high efficiency ( $>$ $92 \%$ ), small size and weight and high reliability. Its functional modules and preliminary results obtained at breadboard level are also presented.

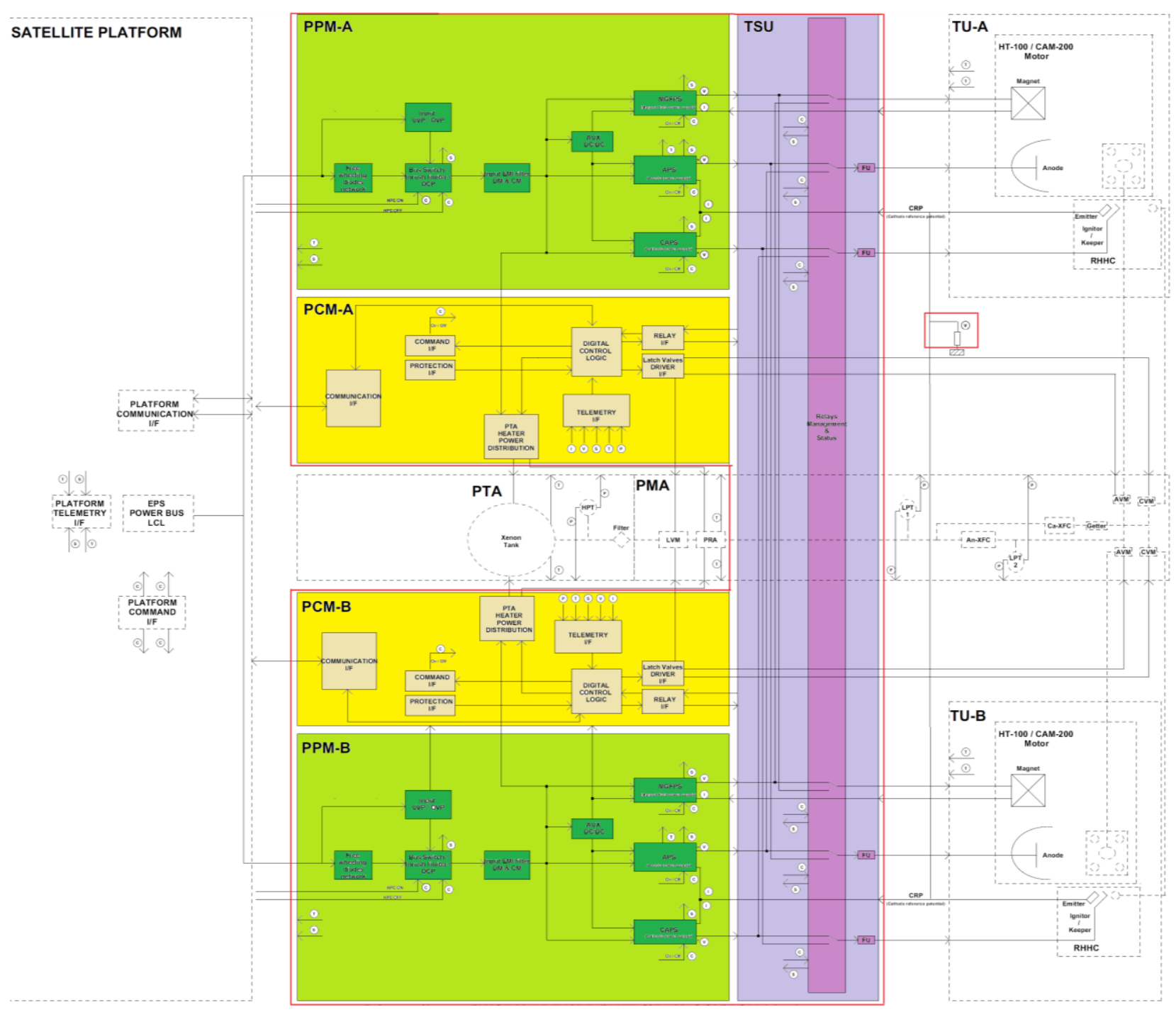

Figure 1. PPU block diagram w.r.t. other EPS elements and Platform. 


\section{INTRODUCTION}

The MEPS program aims at the qualification of an EPS based on low power Hall Effect Thruster (HET).

The EPS consists of two TU each composed of a Thruster/Cathode Assembly, a single PPU and a single Xenon PTA/PMA.

The PPU, whose functional blocks are shown in Fig. 1, is the central part of the EPS. It is supplied by the satellite's Power Distribution Unit (PDU) and provides power conditioning and control for two types of HET ( Sitael's HT100 and Rafael's CAM-200), for Rafael's Heaterless Hollow Cathode (RHHC) and for Rafael's PMA/PTA. The PPU also manages bidirectional communication with the satellite on board computer (OBC).

The PPU has the following main functions:

- power conditioning and monitoring of all voltages and currents required by the EPS in all of its operating modes

- to enable the control of the EPS in order to achieve the best performance according to mission requirements

- to manage bidirectional communication with satellite computer including TM and TC in order to command EPS functions and monitor all EPS relevant parameters

- to ensure isolation between the high voltage electronics that supply the thrusters and the low voltage electronics supplied by the input power bus

- $\quad$ to protect the main bus from the TU EMI

\section{POWER PROCESSING UNIT}

\subsection{General Description}

The PPU enables the single operation of any one of the thrusters in their complete thrust range, ensures full performance for an unregulated power bus voltage from $22 \mathrm{~V}$ to $34 \mathrm{~V}$ and is composed of the following functional blocks:

- PPU Power Module A and B (PPM-A and PPM-B, for redundancy) which implement the power electronic circuits necessary to supply any of the two Thruster Units (TU-A and TU-B)

- Thruster Switching Unit (TSU) which contains the electromechanical circuits enabling the selection of any one of the TUs

- Filter Unit (FU) which has the purpose to filter the high frequency current noise typically associated with the TUs

- PPU Control Module A and B (PCM-A and PCM-B, for redundancy), which provide the communication with the satellite and the control of the PPU and EPS valves.
In order to test the PPU functionalities and to permit the coupling with the TUs, a PPU BB (see Fig. 2) has been assembled and tested.

The breadboard does not implement the redundancy of the final unit; consequently, the TSU is not implemented on the breadboard as well.

In particular the breadboard implements the modules necessary to drive each type of TU:

- Anode Power Supply suitable for both the CAM-200 and HT100

- Cathode Power Supply for the RHHC

- Magnetic Field Power Supply only for the CAM-200 (HT100 has permanent magnets)

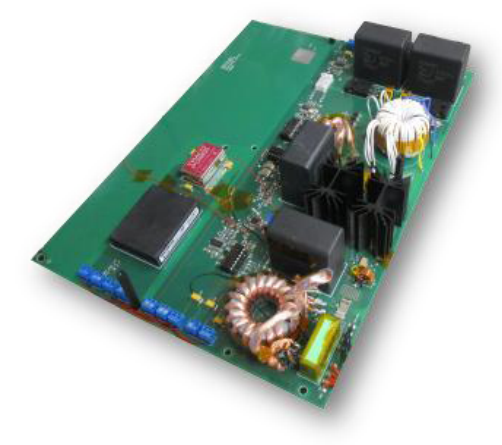

Figure 2. PPU Breadboard detail.

The functions of the PCM necessary to drive the two TUs are implemented using the Labview GUI which is displayed in Fig. 3. The GUI performs the start-up sequence necessary to ignite the cathode and to establish the anode discharge current in automatic mode and is flexible enough to permit the use of each converter independently from the others in manual mode.

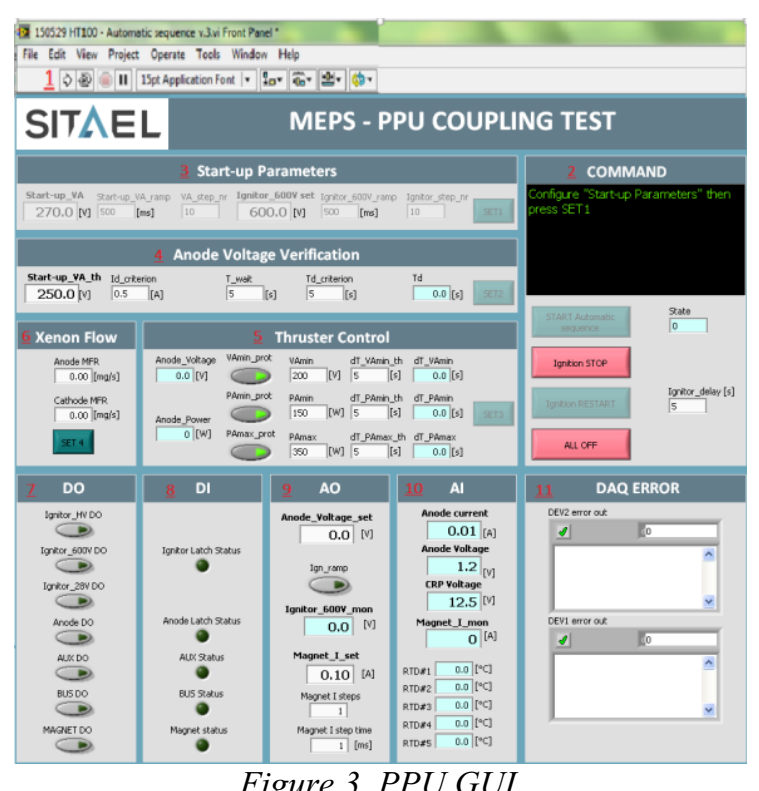

Figure 3. PPU GUI. 


\subsection{PPU Power Module (PPM)}

Each PPM is composed of:

\section{Anode Power Supply (APS)}

The APS supports the plasma discharge current and sets the anode voltage during operation. It is an isolated DC/DC power supply whose output is connected between the thruster anode and the Cathode Reference Potential (CRP). It is supplied by the primary input power Bus downstream the EMI input filter and the inrush current control circuit. It provides:

- Power up to $250 \mathrm{~W}$ to drive the thruster anode

- Acquisition of anode temperature, driving voltage and discharge current

- Regulation of anode voltage according to the thrust required by the satellite $\mathrm{OBC}$. The maximum regulation voltage is $300 \mathrm{~V}$

- Galvanic isolation between input power bus and the thrusters. The isolation voltage is $2500 \mathrm{Vdc}$

The topology selected for the APS DC/DC converter is derived from the Boost-Integrated Half Bridge (BHB) topology which is particularly suitable to provide isolation between a low input voltage source and a high output voltage load thanks to its boosted link voltage. Moreover the continuous input current of the BHB has the advantage to allow the realization of a simple average input current mode control loop and to reduce the EMI. The PPU implementation of the BHB converter presents a modified output stage with respect to the original BHB topology: the output inductor is absent and a voltage doubler replaces the full-wave rectifier. Therefore a magnetic component is avoided, yielding the reduction of weight and power losses, while the transformer realization is simpler because the voltage doubler does not need the central tap of the transformer secondary windings. The simplifications of the magnetics are particularly important as they are a critical part of the design, especially when dealing with high voltages and insulations. Finally, the modified BHB topology allows both Zero Voltage Switching transitions of the primary mosfets and Zero Current Switching transitions of the secondary diodes, permitting high-efficiency even with a relative low power. The APS converter has been initially validated using a dynamic load simulator with an output operating voltage of $300 \mathrm{~V}$ and currents between $0.3 \mathrm{~A}$ and $1 \mathrm{~A}$, which are encountered with the various flow rates. Fig. 4 presents the test results at three input voltages $(22,28$ and 34 Volts) with dummy resistive loads.

An important detail of the PPU EM design regards the implementation of the output current and voltage telemetries. Since high accuracy is required on all TU measurements, it was preferred to perform the analogue to digital conversion directly on the secondary and to realize the isolation using a digital isolator based on magnetic coupling, implemented using discrete components.

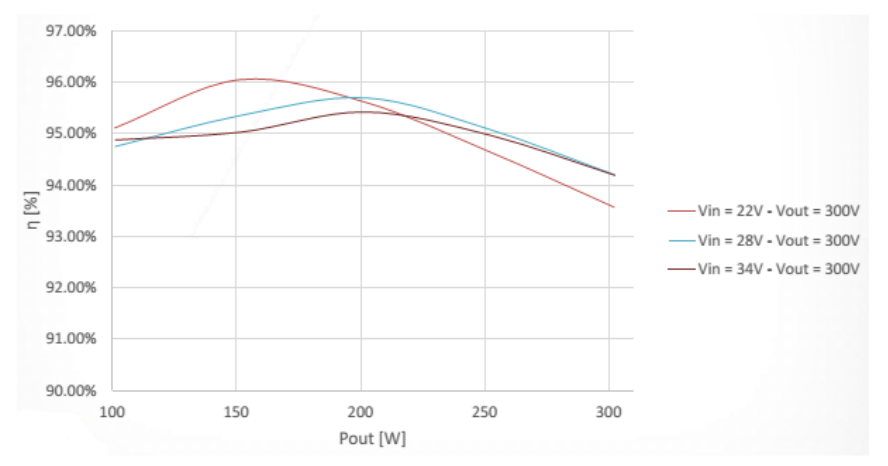

Figure 4. Efficiency for Vout $300 \mathrm{~V}$ and different Input Voltages.

Magnetic Field Power Supply (MGFPS)

MGFPS is an isolated DC/DC settable current source whose purpose is to supply the magnetic field coils of the CAM-200 thruster with a current up to $3.5 \mathrm{~A}$.

The MGFPS is connected to the unregulated bus coming from the PDU downstream the EMI input filter and inrush current control circuit

In order to improve the efficiency and reliability of the PPU EM, the EM implementation of the MGFPS will be with only one isolated conversion stage with forward topology.

\section{Cathode Power Supply (CAPS)}

CAPS is an isolated DC/DC Power Supply providing the following features:

- High voltage driving of thruster Cathode during the breakdown phase which is expected to be lower than $1200 \mathrm{~V}$

- Current driving during keeping phase

- Acquisition of cathode driving voltage and current

- Filtering of the noise generated by the cathode during ignition

- Galvanic isolation between input power bus and the thruster and the chassis. The isolation voltage is $2500 \mathrm{Vdc}$.

Fig. 5 depicts the block schematics of the Cathode power supply implemented for the PPU BB.

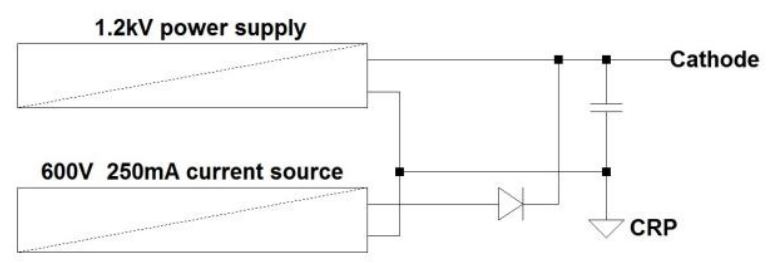

Figure 5. CAPS simplified diagram. 
In order to achieve the flexibility necessary to support the testing of the RHCC, the CAPS module is implemented using two different and separately tunable power supplies, each taking care of one of the two phases of the cathode power up sequence which are represented in Fig. 6 and described hereafter:

- The Breakdown phase is the first stage of the cathode ignition sequence. In this phase cathode supply serves as discharge initiator to the cathode. The breakdown pulse is applied in order to ionize a low Xenon flow rate, passing through the cathode and creates an arc discharge between the emitter and keeper. At the breakdown phase the cathode will be driven by a discharge capacitor, whose value can be changed between $220 \mathrm{nF}$ and $1 \mathrm{uF}$ on the PPU BB in order to tune the energy delivered to the ignitor during breakdown. The ignition phase is obtained by means of a $1200 \mathrm{~V}$ power supply driven by a current source in order to simulate the behavior of a current generator charging the output capacitor with a constant current. The design of the isolation stage is based on the same architecture used for the APS.

- The Keeping phase is the phase which aims to raise cathode temperature to favor the thermionic emission. During this stage the current within the cathode is controlled by an isolated $\mathrm{DC} / \mathrm{DC}$ converter.

During this phase the current is limited to $250 \mathrm{~mA}$ and the maximum voltage is clamped to $600 \mathrm{~V}$. The maximum voltage limit is settable in order to allow some flexibility during the test of the cathode.

The design of the isolation stage is based on the same architecture used for the APS.

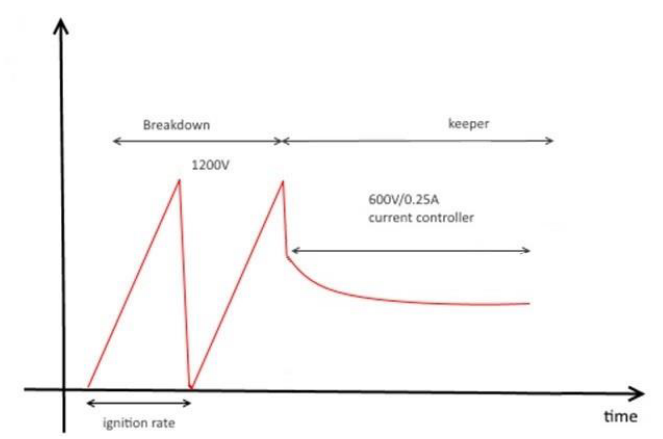

Figure 6. CAPS sequence.

\section{Auxiliary Power Supply (AUX)}

The galvanically insulated Auxiliary DC/DC converter provides all the housekeeping supplies necessary to the PPU modules and the auxiliary supplies to control the PMA/PTA fluidic subsystem. The Auxiliary converter design for the PPU EM consists in a multiple output Forward converter with peak current mode control.

\subsection{Filter Unit (FU)}

FU is a passive low pass LC filter with resistive damping which is aimed at reducing the high frequency noise current generated by the TU during its operation.

The capability of FU will be evaluated during the coupling test activities and its operation shall be optimized in order to be compatible with the EMC/ESD requirements.

\subsection{PPU Control Module (PCM)}

The EPS is externally controllable by the spacecraft's OBC while its internal control is performed by the PCM. In particular the PCM controls the APS, CAPS and MGFPS, the TSU high voltage relays and the PMA/PTA valves so as to enable the driving and control of one thruster at a time.

Specifically, the PCM provides the following features:

- Temperature monitor via thermal sensors located in the thrusters and PMA

- Anode, cathode and magnetic field driving voltages and currents monitors

- Heaters and valves driving currents monitors

- Output signals voltages and currents monitor

- Voltage settings for APS and current settings for MGFPS

- Sequencing and management of thruster's operation in various modes (i.e. start-up, shutdown, power setting, thrust regulation and failure recovery)

- Management of MEPS redundancy policy, in particular commanding the TSU

- Management of Telecommand / Telemetry communication

The PCM will be an FPGA-based digital board including non-volatile memory with EDAC for parameters storage, DAC control for Anode and Cathode voltages, ADCs and MUXs (with relative signals conditioning circuits) for external/internal sensors/voltages readout.

The FPGA approach will make the programmed sequences control more flexible with the possibility of adjusting the internal parameters.

The PCM is not considered critical part. Thus, it is being directly developed at EM level.

\subsection{Thruster Switching Unit (TSU)}

The TSU provides the means to enable the active selection between the two TUs, disconnects the possibly failed thruster from PPMs and connects the isolated TU to a resistive network in order to avoid its complete floating. The switching function is performed by high voltage relays which are operating while PPM supplies are OFF in order to avoid electric arcs.

\section{COUPLING TESTS}

Coupling tests have been performed in order to verify the capability of the PPU BB to ignite the two TUs (Rafael's CAM-200 with RHHC and Sitael's HT100 with RHHC) and keep the discharge stably on in steady state condition 
for different power levels. The test setup used is presented in Fig. 7.

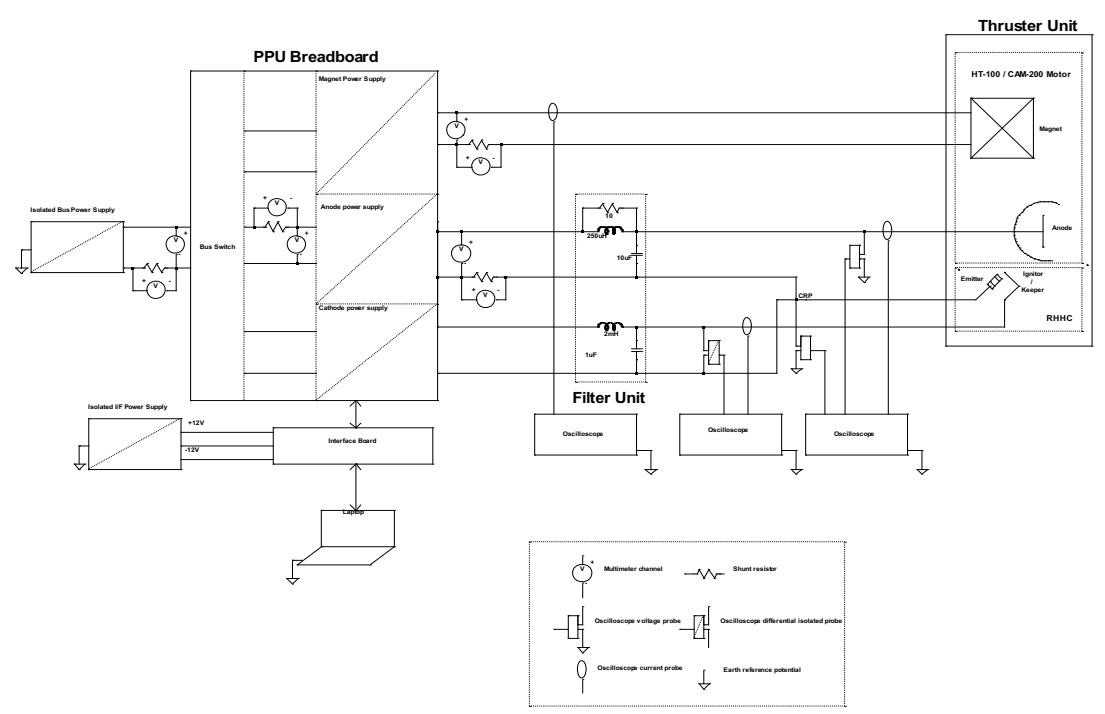

Figure 7. Coupling test setup.

For the needs of the tests, Sitael's IV4 vacuum chamber has been used.

The operating points tested are indicated in Tab. 1 and 2 respectively for both TUs in the preliminary phase (each TU was coupled with a laboratory PPU) and in the coupling phase with the PPU BB.

Table 1. HT100 Operating points verified during the coupling test with PPU BB.

\begin{tabular}{|c|c|c|c|c|}
\hline $\begin{array}{c}\text { Operating } \\
\text { Point }\end{array}$ & $\begin{array}{c}\text { Power, } \\
{[\mathbf{W}]}\end{array}$ & $\begin{array}{c}\dot{m}_{A}, \\
{[\mathbf{m g} / \mathbf{s}]}\end{array}$ & $\begin{array}{c}\dot{m}_{C}, \\
{[\mathbf{m g} / \mathbf{s}]}\end{array}$ & $\begin{array}{c}\boldsymbol{V}_{\boldsymbol{d c}}, \\
{[\mathbf{V}]}\end{array}$ \\
\hline 1 & 130 & 0.6 & 0.25 & 300 \\
\hline 2 & 160 & 0.75 & 0.25 & 275 \\
\hline 3 & 190 & 0.75 & 0.25 & 325 \\
\hline 4 & 220 & 1 & 0.25 & 275 \\
\hline 5 & 250 & 1 & 0.25 & 300 \\
\hline
\end{tabular}

Table 2. CAM-200 Operating points verified during the coupling test with PPU BB.

\begin{tabular}{|c|c|c|c|c|c|}
\hline $\begin{array}{c}\text { Operating } \\
\text { Point }\end{array}$ & $\begin{array}{c}\text { Power, } \\
{[\mathbf{W}]}\end{array}$ & $\begin{array}{c}\dot{m}_{A}, \\
{[\mathrm{mg} / \mathbf{s}]}\end{array}$ & $\begin{array}{c}\dot{m}_{C}, \\
{[\mathbf{m g} / \mathbf{s}]}\end{array}$ & $\begin{array}{c}\boldsymbol{V}_{\boldsymbol{d c}}, \\
{[\mathbf{V}]}\end{array}$ & $\begin{array}{c}\boldsymbol{I}_{\text {mag }}, \\
{[\mathbf{A}]}\end{array}$ \\
\hline 1 & 110 & 0.62 & 0.25 & 250 & 2 \\
\hline 2 & 130 & 0.69 & 0.25 & 250 & 2.5 \\
\hline 3 & 160 & 0.75 & 0.25 & 275 & 2.5 \\
\hline 4 & 180 & 0.83 & 0.25 & 275 & 2.5 \\
\hline 5 & 200 & 0.90 & 0.25 & 275 & 2.5 \\
\hline
\end{tabular}

\subsection{Coupling test results for CAM-200}

The coupling test with the PPU BB succeeded the ignition of the CAM-200 thruster in all operating points.
Tab. 3 and Fig. 8 present the efficiency of the APS recorded for the various operating points of the CAM200 thruster for three different input voltages 22, 28 and 34 volts.

Table 3. CAM-200 Anode efficiency.

\begin{tabular}{|l|l|l|l|l|l|l|l|}
\hline $\begin{array}{c}\mathbf{A}_{\text {MFR }} \\
{[\mathbf{m g} / \mathbf{s}]}\end{array}$ & $\begin{array}{c}\mathbf{C}_{\text {MFR }} \\
{[\mathbf{m g} / \mathbf{s}]}\end{array}$ & $\begin{array}{l}\mathbf{V}_{\text {in }} \\
{[\mathbf{V}]}\end{array}$ & $\begin{array}{l}\mathbf{V}_{\text {OUT_AN }}[\mathbf{V}] \\
{\left[\begin{array}{l}\mathbf{I}_{\text {OUT_AN }} \\
{[\mathbf{A}]}\end{array}\right.}\end{array}$ & $\begin{array}{l}\mathbf{P}_{\text {OUT_AN }} \\
{[\mathbf{W}]}\end{array}$ & $\begin{array}{l}\mathbf{n}_{\text {AN }} \\
{[\%]}\end{array}$ & $\begin{array}{l}\mathbf{T}_{\text {An_MFET }} \\
{\left[{ }^{0} \mathbf{C}\right]}\end{array}$ \\
\hline 0.62 & 0.25 & 22 & 250 & 0.458 & 114 & 93.9 & 33.60 \\
\hline 0.69 & 0.25 & 22 & 250 & 0.513 & 128 & 93.7 & 31.30 \\
\hline 0.75 & 0.25 & 22 & 275 & 0.578 & 159 & 94.3 & 33.10 \\
\hline 0.83 & 0.25 & 22 & 275 & 0.648 & 178 & 93.9 & 35.00 \\
\hline 0.9 & 0.25 & 22 & 274 & 0.710 & 195 & 93.8 & 35.60 \\
\hline 0.62 & 0.25 & 28 & 251 & 0.458 & 115 & 93.1 & 36.10 \\
\hline 0.69 & 0.25 & 28 & 251 & 0.512 & 129 & 93.5 & 32.10 \\
\hline 0.75 & 0.25 & 28 & 275 & 0.573 & 157 & 94.1 & 34.30 \\
\hline 0.83 & 0.25 & 28 & 276 & 0.648 & 179 & 94.0 & 34.30 \\
\hline 0.9 & 0.25 & 28 & 275 & 0.711 & 196 & 93.9 & 36.20 \\
\hline 0.62 & 0.25 & 34 & 251 & 0.457 & 114 & 92.2 & 36.10 \\
\hline 0.69 & 0.25 & 34 & 251 & 0.513 & 129 & 92.9 & 34.80 \\
\hline 0.75 & 0.25 & 34 & 275 & 0.576 & 158 & 93.4 & 36.10 \\
\hline 0.83 & 0.25 & 34 & 275 & 0.648 & 178 & 93.6 & 34.30 \\
\hline 0.9 & 0.25 & 34 & 276 & 0.711 & 196 & 93.7 & 36.60 \\
\hline
\end{tabular}

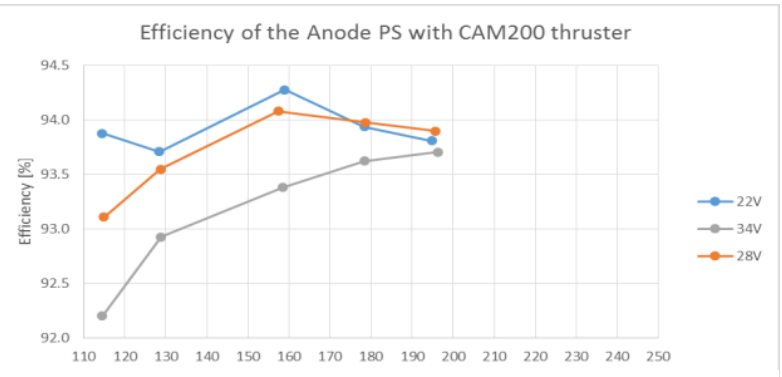

Figure 8. Anode efficiency with CAM-200.

Start-up and steady state plots were recorded for the various operating points and are presented in Fig. 9 and 10 respectively. The waveforms presented in the plots are the following: 


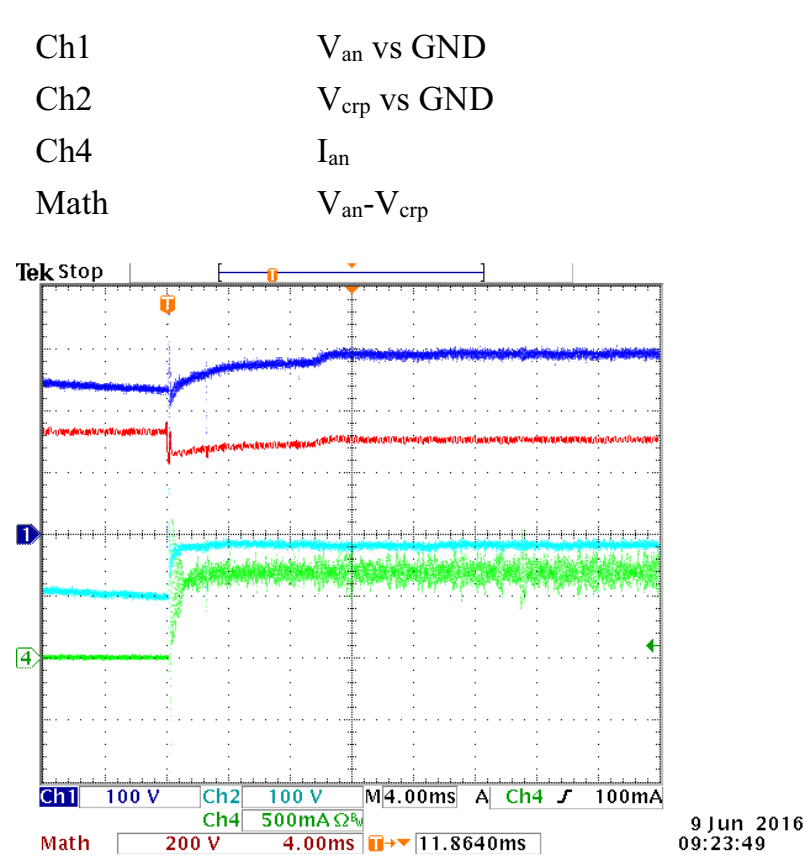

Figure 9. CAM-200 Anode start-up current and voltage with Xe_MFR $=0.83 \mathrm{mg} / \mathrm{s}$ and output voltage set to $300 \mathrm{~V}$. Magnet current is $2.5 \mathrm{~A}$.

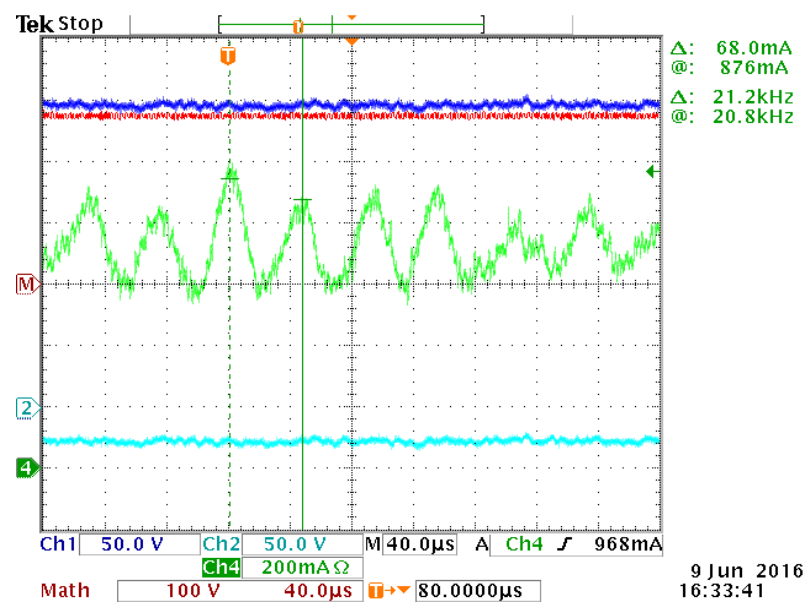

Figure 10. CAM-200 Anode steady state current and voltage with Xe_MFR $=0.75 \mathrm{mg} / \mathrm{s}$ and output voltage set to $275 \mathrm{~V}$. The characteristic frequency of the anode current is about $20 \mathrm{kHz}$ for the CAM-200.

\subsection{Coupling test results for HT100}

The coupling test with the PPU BB succeeded the ignition of the HT-100 thruster in all operating points. Tab. 4 and Fig. 11 present the efficiency of the APS for three different Input Voltages 22, 28 and 34 volts.

Table 4: Anode efficiency with HT100.

\begin{tabular}{|l|l|l|l|l|l|l|l|}
\hline $\begin{array}{c}\mathbf{A}_{\text {MFR }} \\
{[\mathbf{m g} / \mathbf{s}]}\end{array}$ & $\begin{array}{c}\mathbf{C}_{\text {MFR }} \\
{[\mathbf{m g} / \mathbf{s}]}\end{array}$ & $\begin{array}{c}\mathbf{V}_{\text {in }} \\
{[\mathbf{V}]}\end{array}$ & $\begin{array}{l}\mathbf{V}_{\text {OUT_AN }} \\
{[\mathbf{V}]}\end{array}$ & $\begin{array}{l}\mathbf{I}_{\text {OUT_AN }}[\mathbf{A}] \\
{\left[\begin{array}{l}\text { P }] \\
{[\mathbf{W}]}\end{array}\right.}\end{array}$ & $\begin{array}{c}\mathbf{P}_{\text {AN }} \\
{[\%]}\end{array}$ & $\begin{array}{l}\mathbf{T}_{\text {An_MFET }} \\
{\left[{ }^{\mathbf{0}} \mathbf{C}\right]}\end{array}$ \\
\hline 0.6 & 0.25 & 22 & 300 & 0.460 & 138 & 94.0 & 34.30 \\
\hline 0.75 & 0.25 & 22 & 275 & 0.583 & 160 & 94.2 & 35.70 \\
\hline 1 & 0.25 & 22 & 325 & 0.569 & 185 & 94.6 & 36.60 \\
\hline 1 & 0.25 & 22 & 275 & 0.824 & 227 & 93.2 & 41.30 \\
\hline
\end{tabular}

\begin{tabular}{|l|l|l|l|l|l|l|l|}
\hline $\begin{array}{c}\mathbf{A}_{\text {MFR }} \\
{[\mathbf{m g} / \mathbf{s}]}\end{array}$ & $\begin{array}{c}\mathbf{C}_{\text {MFR }} \\
{[\mathbf{m g} / \mathbf{s}]}\end{array}$ & $\begin{array}{l}\mathbf{V}_{\text {in }} \\
{[\mathbf{V}]}\end{array}$ & $\begin{array}{l}\mathbf{V}_{\text {OUT_AN }} \\
{[\mathbf{V}]}\end{array}$ & $\begin{array}{l}\mathbf{I}_{\text {OUT_AN }} \\
{[\mathbf{A}]}\end{array}$ & $\begin{array}{l}\mathbf{P}_{\text {OUT_AN }} \\
{[\mathbf{W}]}\end{array}$ & $\begin{array}{c}\mathbf{n}_{\text {AN }} \\
{[\%]}\end{array}$ & $\begin{array}{l}\mathbf{T}_{\text {An_MFET }} \\
{\left[{ }^{\mathbf{0}} \mathbf{C}\right]}\end{array}$ \\
\hline 0.6 & 0.25 & 28 & 301 & 0.460 & 138 & 93.7 & 35.10 \\
\hline 0.75 & 0.25 & 28 & 275 & 0.582 & 160 & 94.0 & 36.10 \\
\hline 0.75 & 0.25 & 28 & 326 & 0.570 & 186 & 94.6 & 37.60 \\
\hline 1 & 0.25 & 28 & 275 & 0.824 & 227 & 93.6 & 41.30 \\
\hline 1 & 0.25 & 28 & 301 & 0.823 & 247 & 94.0 & 42.30 \\
\hline 0.6 & 0.25 & 34 & 301 & 0.460 & 139 & 93.1 & 35.90 \\
\hline 0.75 & 0.25 & 34 & 275 & 0.582 & 160 & 93.5 & 38.30 \\
\hline 0.75 & 0.25 & 34 & 328 & 0.570 & 187 & 93.8 & 38.70 \\
\hline 1 & 0.25 & 34 & 275 & 0.824 & 227 & 93.3 & 41.80 \\
\hline 1 & 0.25 & 34 & 301 & 0.822 & 247 & 93.8 & 41.40 \\
\hline
\end{tabular}

Efficiency of the Anode PS with HT100 thruster

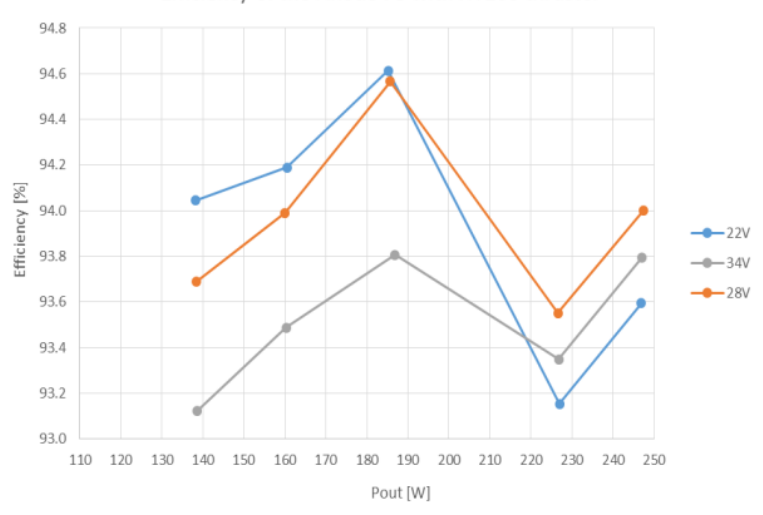

Figure 11. HT100 Anode efficiency.

Start-up and steady state plots were recorded for the various operating points and images of the anode and cathode waveforms are presented in Fig 12. The waveforms presented are the following:

$\begin{array}{ll}\text { Ch3 } & \mathrm{V}_{\text {cath }} \text { vs } \mathrm{V}_{\text {crp }} \\ \text { Ch4 } & \mathrm{I}_{\text {an }} \\ \text { Math } & \mathrm{V}_{\text {an }}-\mathrm{V}_{\text {crp }}\end{array}$

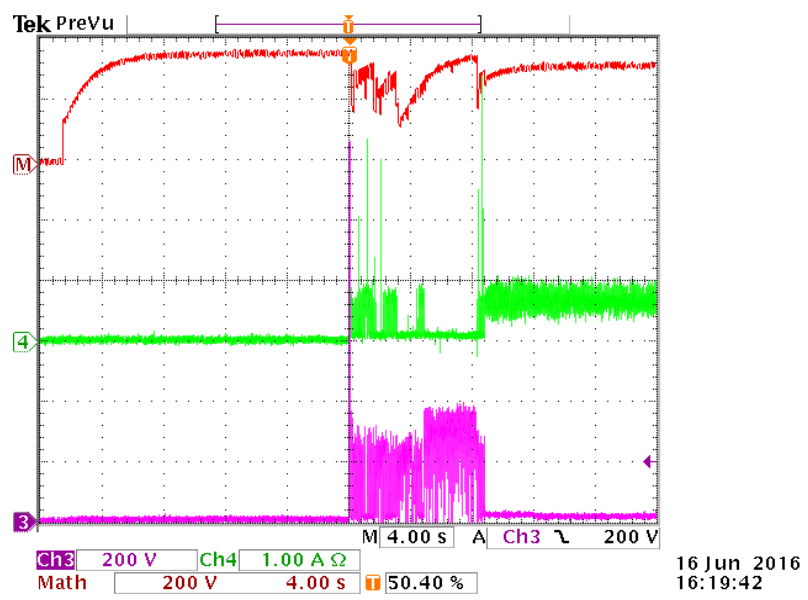

Figure 12. HT100 power-up sequence and switch-on transient with $A N \_X e \_M F R=0.75 \mathrm{mg} / \mathrm{s}$ and

CAT_Xe_MFR $=0.25 \overline{\mathrm{mg}} / \mathrm{s}$. Output voltage set to $325 \mathrm{~V}$. The cathode switches on at maximum voltage (1200V). 
The plot shows the sequence used for the start-up:

- Initially the anode voltage is applied to the APS.

- The HV module and cathode power supply are then switched on.

- Cathode breakdown occurs at maximum voltage (1200V) and a current limited phase (keeping phase) follows. During this phase the current is limited to $250 \mathrm{~mA}$.

- The anode's discharge starts occurring and once the steady state phase is reached the keeping phase is terminated.

Fig. 13 and 14 represent a detail of the cathode voltage and current during breakdown transient and the inception of keeping phase respectively.

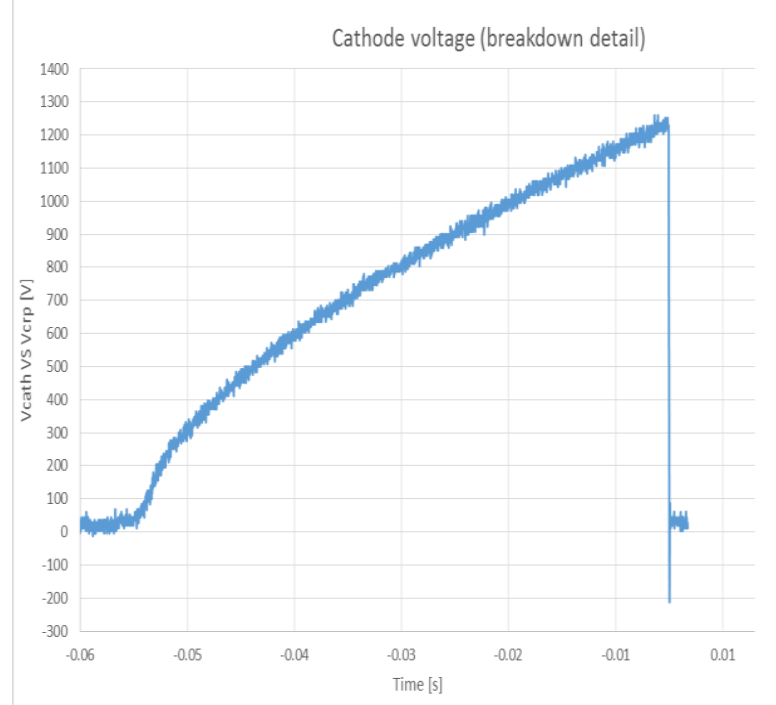

Figure 13. Cathode voltage during breakdown.

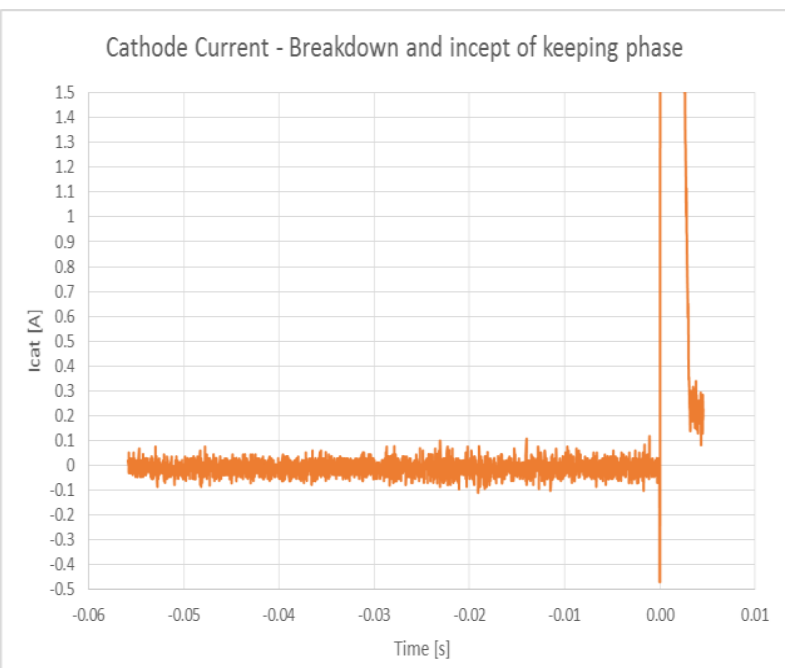

Figure 14. Cathode current transition from breakdown to keeping phase.
Finally, the steady state waveforms are presented in Fig. 15. The waveforms presented are:

$\begin{array}{ll}\text { Ch1 } & \mathrm{V}_{\text {cath }} \text { vs } \mathrm{V}_{\text {crp }} \\ \mathrm{Ch} 3 & \mathrm{I}_{\text {cath }} \\ \text { Ch4 } & \mathrm{I}_{\text {an }}\end{array}$

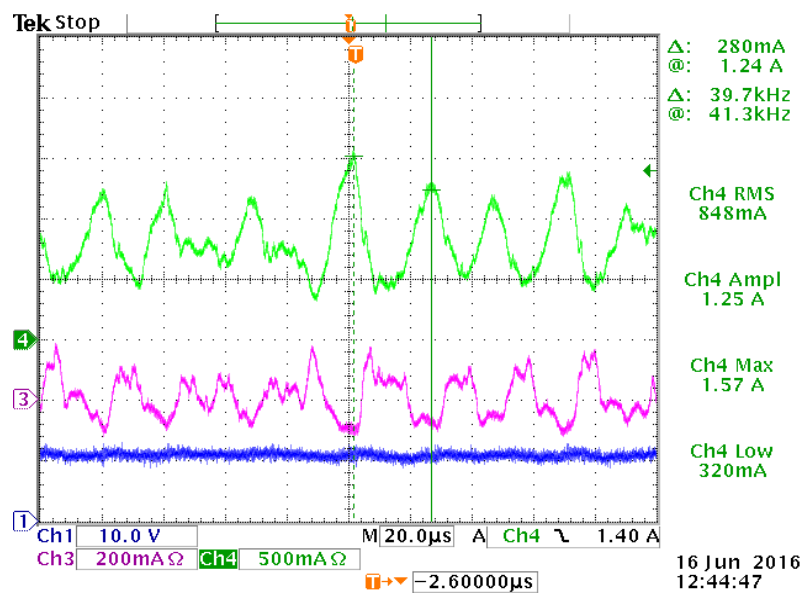

Figure 15. HT100 Anode steady state current and Cathode current with $A N \_X e_{-} M F R=1 \mathrm{mg} / \mathrm{s}$ and

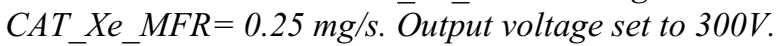
The characteristic frequency of the anode current is about $40 \mathrm{kHz}$ for the HT100.

Fig. 16 presents an image of the HT100 thruster and RHHC firing in the IV4 Sitael vacuum chamber facility after their successful ignition during the coupling tests with the PPU.

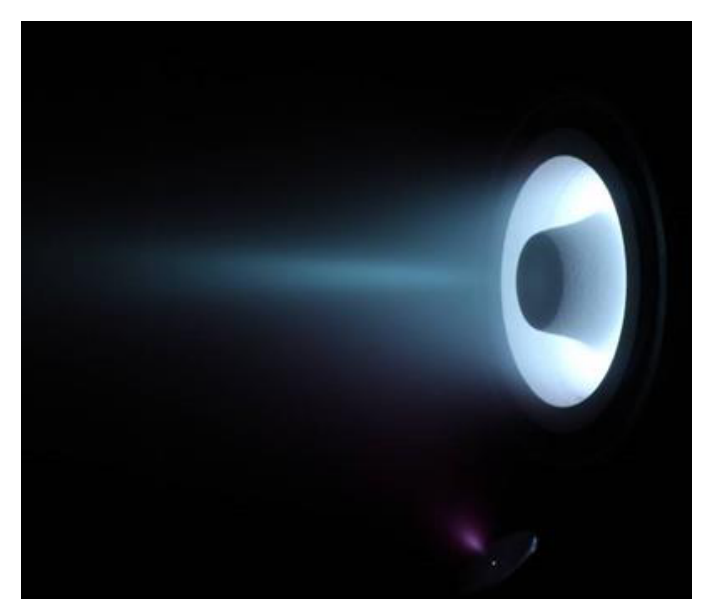

Figure 16. HT100 and RHHC firing during the coupling test with MEPS PPU.

\section{FUTURE ACTIVITIES}

The most critical parts of the PPU design have been evaluated by the means of the modular PPU BB and are currently being updated for the EM phase. Moreover, some of the PPU functional blocks need to be designed 
from the beginning as they were not considered critical. After the EM implementation and validation, which will involve a complete coupling with the TUs and the PMA/PTA subsystems, the QM will be realized and qualified.

\section{CONCLUSIONS}

In the framework of MEPS program an EPS based on low power HET is going to be qualified. Sitael Hellas, supported by Sitael is responsible for the design of the PPU. This PPU is suitable for both Sitael HT100 and Rafael CAM-200 HET. The operational design principles of the proposed DC/DC converters and of all the power modules have been discussed and their advantages have been described.

MEPS PPU BB implementation has been briefly described and the coupling test results have been presented. The PPU BB contains critical parts of the design and has been successfully coupled to HT100 and CAM-200 thrusters, in particular the CAPS and the APS have been able to switch on both thrusters in any operating point and provide efficiency higher than $93 \%$ in a power range between $130 \mathrm{~W}$ to $250 \mathrm{~W}$.

PPU's final development will display considerable technological aspects in the existing space systems:

- High Efficiency: PPU is designed to exceed $92 \%$ efficiency.

- High Reliability: PPU is designed to have reliability higher than 0.99. Redundancy is assessed on the critical parts of the PPU, at module level.

- Small Budget: PPU will include both TSU and FU with an the envelope of $300 \mathrm{~mm} \times 240 \mathrm{~mm} \times 230 \mathrm{~mm}$ (L x W x H) volume

Optimization of the PPU behaviour is foreseen during the next stages of the project (EM and QM). On the road towards the EM that is currently being developed, a complete boards' layout as well as, the housing and mechanical design have been implemented and two representative images are presented in Fig. 17 and 18.

\section{REFERENCES}

1. T. Misuri, R. Albertoni, C. Ducci, B. Waldvogel, L. Appel, R. Eytan, D. Lev, K. Dannenmayer, D. Di Cara, "MEPS: A Low Power Electric Propulsion System for Small Satellites", 10th IAA Symposium on Small Satellites for Earth Observation, Berlin, Germany, 20-23 April 2015

2. T. Misuri, C. Ducci, R. Albertoni, M. Andrenucci, D. Pedrini, "Sitael Low Power Hall Effect Thrusters for Small Satellites", IEPC-2015-102 ISTS-2015-b-102, Kobe, Japan, 1-10 July 2015

3. Amoz Davidson, Pavel Gontmacher, Jacob Herscovitz, and Igal Tidhar. "Development, Qualification and Integration of the VEN $\mu$ S PPU", 50th AIAA/ASME/SAE/ASEE Joint Propulsion Conference, Propulsion and Energy Forum, (AIAA 2014-3608).

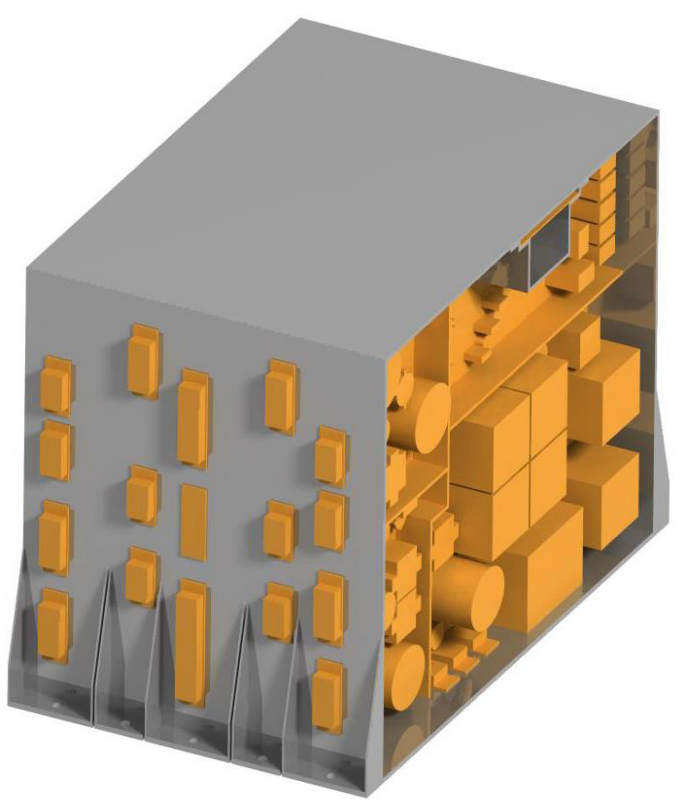

Figure 17. Mechanical design (Courtesy of INASCO Hellas).

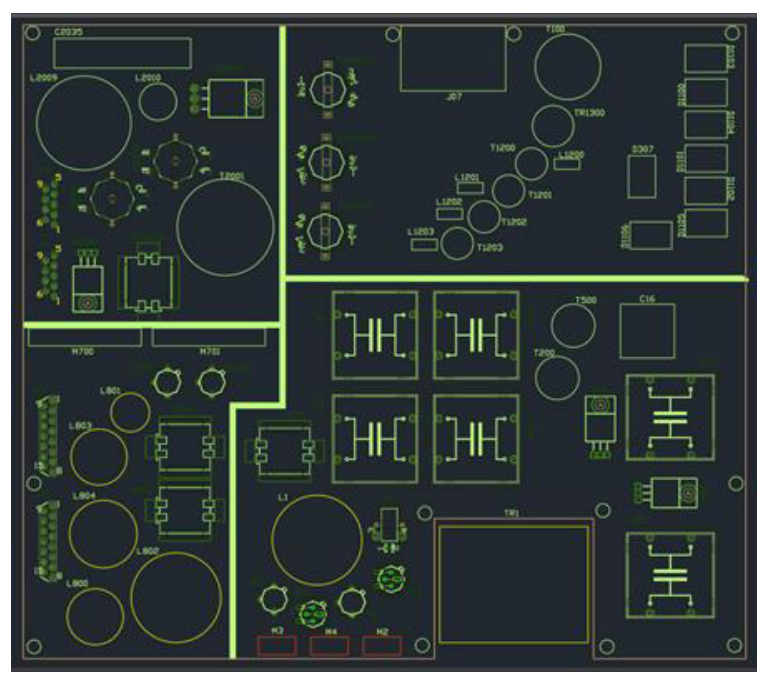

Figure 18. APS Board layout. 